\title{
Own a Pet - Stay well and Happy : an exploratory study
}

\author{
Shreya Chaudhary ${ }^{1}$, S.K. Srivastava ${ }^{2}$ \\ ${ }^{1}$ Research Scholar, Gurukul Kangri University, Haridwar, Uttarakhand, India. \\ ${ }^{2}$ Professor, Department of Psychology, Gurukul Kangri University, Haridwar, Uttarakhand, India. \\ Corresponding author: Shreya Chaudhary \\ E-Mail: shreyachaudhary1611@gmail.com
}

\begin{abstract}
Background: Pets seem like perfect companions providing unconditional love without any expectation from owner. Pets can be seen as stress reducer and being looked upon as companions and members of the family. The purpose of this study was to examine the effect of pet ownership on happiness, psychological well-being in pet owners and non-pet owners.

Methodology: Data was collected from 100 participants. Data was gathered by means of questionnaires that assessed happiness, psychological well-being. The Ryff scale of psychological well-being and subjective happiness scale have been employed. The data were analyzed by employing mean, SD and t- tests.

Results: Results of this study showed that there is significant difference in levels of happiness and psychological well-being experienced by pet owners and non-pet owners.
\end{abstract}

Keywords: happiness, psychological well-being, pets, wellness

(Paper received $-17^{\text {th }}$ October 2017, Peer review completed $-23^{\text {th }}$ November 2017)

(Accepted $-28^{\text {th }}$ November 2017)

\section{INTRODUCTION}

Pets have always been a craze in western world but this trend has started recently in India. Companionship between animals and humans has been an intriguing phenomenon since prehistoric times. Pets are also considered as fashion accessories in celebrity culture. Pets are being looked upon as companions and members of the family. People have their own reason for keeping pets like to have loving companion, entertainment watchdogs, boost social life, trend etc. Career oriented women are marrying late and therefore, there exists a greater propensity among them to own pets for companionship. The one-child norm and trend of nuclear families has also leaded to more families keeping pets [1]. Keeping pets is an important part of many people's lives in this era. People no longer refer to themselves as pet owners, but they like to be called as 'proud pet parents'. And speaking of parenthood, many see pets as the first extension of their family, before having children. A leading newspaper daily reports that $70 \%$ of the Hindi film industry is known to own at least one dog. According to the National Pet Owners Survey, about twothirds of U.S. households own at least one pet, which means 71 million homes provide shelter for at least one furry, feathery or scaly critter [2]. The pet population in India has grown from 7 million in 2006 to 10 million in 2014, on an average 600,000 pets are adopted every year. Cat ownership is increasing in India, presently there are 40 lacs cats in the country, out of these 20 lacs in urban India and 20 lacs in rural India [3].

In recent decades, positive psychology has tried to devote attention to humans' abilities. "This science is currently known as having done comprehensive studies for well-being and happiness in different 
educational, hygienic, therapeutic and academic realms [4]. Happiness and well-being are complicated constructs. Psychological well-being studied extensively as there is a need to improve the state of mental conditions of people. The concept of happiness is the corner stone of the assumptions of positive psychology. Happiness is characterized by the experience of more frequent positive affective states than negative ones as well as a perception that one is progressing toward important life goals [5]. Happiness depends on ourselves. More than anybody else, Aristotle enshrines happiness as a central purpose of human life and a goal in itself. Everyone wants to be happy. Happiness is one of such positive characteristics which need to be focused in the contemporary society. Happiness can be defined as an individual's global assessment of positive/ negative emotional experiences and satisfaction with life. Indeed, happiness may be the ultimate fundamental 'goal' that people pursue in their lives [6]. Happiness is the degree to which a person evaluates the overall quality of his present life-as-a-whole positively. In other words, how much one likes the life one lives in his present situation.

Well-being generally includes global judgments of life satisfaction and feelings ranging from depression to joy [7-8]. Psychological well-being is attained by achieving a state of balance affected by both challenging and rewarding life events [9]. Psychological well-being consists of positive relationships with others, personal mastery, autonomy, a feeling of purpose and meaning in life, and personal growth and development [10]. Psychological Well-being refers to the simple notion of a person's welfare, happiness, advantages, interests, utility, and quality of life [11]. Psychological well-being is usually conceptualized as some combination of positive affective states such as happiness (the hedonic perspective) and functioning with optimal effectiveness in individual and social life (the eudaimonic perspective) [12]. Interacting with pets can also help to release endorphins into the brain. Many hospitals now include a pet therapy programme, aimed to make patients feel relaxed and comfortable by having animals around in a medical environment. The positive interaction with pet animals has also been proven to speed up the patient recovery process. Companion animals also resulting in benefiting various aspects of physiological health in humans but also contribute to the psychological well-being of people. Dogs may not only be able to facilitate certain aspects of physiological health in humans, they may also contribute towards the psychological well-being of people [12]. The first demonstration of an association between pets and health was an early study of 92 heart-attack victims in which $28 \%$ of pet owners survived for at least a year as compared to only $6 \%$ of non-pet owners [13]. Many studies show that greater social support improves psychological well-being [14]. McConnell and others [15] concluded that pet owners had greater selfesteem, greater levels of exercise and physical fitness, and they tended to be less lonely than non- pet owners. Although the other well-being measures descriptively suggested more positive wellbeing for owners relative to non- pet owners, none of these differences were reliable though there was evidence on half of the wellbeing measures that pet owners fared better than non- pet owners. Bao and Schreer [16] found that pet owners were more satisfied with their lives than non- pet owners, but did not differ on other wellbeing measures, personality measures, emotion regulation, or need satisfaction. Dog owners scored higher on all aspects of wellbeing compared with cat owners, and differed on a number of other measures.

\section{METHODOLOGY}

\section{Hypotheses}

1. There would be no significant difference on happiness scores between pet owners and non- pet owners.

2. There would be no significant difference on psychological well-being scores between pet owners and non- pet owners.

\section{Sample}

The sample comprised of 100 subjects living in residential areas of in different areas of Hardwar district of the state Uttarakhand (India). The pet owner group consisted of 50 subjects among whom were $35 \mathrm{dog}$ owners and 15 cat owners. The non-pet owner group consisted of 50 subjects. The sample ranged in age from 15 years to 65 years old. Among the respondents, $80 \%$ were female, and $20 \%$ were male and were belonging to higher socio-economic statuses. The majority of the respondents worked in the private sector 
(55\%) and were self-employed (20\%). The purposive sampling technique was used for selection of sample. When describing the breed of dog that the subjects had, dog owners had Pug (31.4\%), followed by Labrador (20\%), Cocker Spaniel (14.2\%) and German Shepherds (8.5\%). Other breeds of dogs were less commonly found in the sample. Among the cat owners, $40 \%$ had Persian cats. Other cat owners had local breed or mixed breed.

\section{Test materials used}

The following tool was used in the present investigation:

- The Ryff scales of Psychological Well-Being: The short form of the Ryff inventory which consists of 18 items was used. The inventory consists of a series of statements reflecting the six areas of psychological well-being: autonomy, environmental mastery, personal growth, positive relations with others, purpose in life, and self-acceptance. Respondents rate statements on a scale of 1 to 6 , with 1 indicating strong disagreement and 6 indicating strong agreement. Internal consistencies varied between 0.87 and 0.93 and test-retest reliability coefficient ranged between 0.81 and 0.85 [9].

- Subjective Happiness Scale (SHS): The SHS is developed by Lyubomirsky and Lepper [17], a 4item scale of global subjective happiness. Two items ask respondents to characterize themselves using both absolute ratings and ratings relative to peers, whereas the other two items offer brief descriptions of happy and unhappy individuals and ask respondents the extent to which each characterization describes them.

\section{Procedure}

The subjects were approached and the purpose of research was clearly stated to them and confidentiality was assured. The willingness to participate was sought and questionnaires were administered. The responses of the subjects were scored as per the manual for questionnaire. It was subjected to statistical analysis and results were obtained.

\section{RESULTS}

Table 1 - Happiness scores of pet owners and non-pet owners

\begin{tabular}{|l|l|l|l|l|}
\hline Group & $\mathbf{N}$ & Happiness scores & t-value \\
\cline { 3 - 4 } & & Mean & SD & \multirow{2}{*}{$4.42^{* *}$} \\
\hline Pet Owners & 50 & 17.8 & 6.66 & \\
\hline Non-Pet Owners & 50 & 12.4 & 5.54 & \\
\hline \multicolumn{2}{|l}{ significant at 0.01 level } \\
\end{tabular}

Table 2 - Psychological well-being scores of pet owners and non-pet owners

\begin{tabular}{|l|l|l|l|l|}
\hline \multirow{2}{*}{ Group } & \multirow{2}{*}{} & \multicolumn{2}{|l|}{ Psychological well-being scores } & \multirow{2}{*}{ t-value } \\
\cline { 3 - 4 } & & Mean & SD & \\
\hline Pet Owners & 50 & 70.8 & 33.4 & $2.34^{*}$ \\
\hline Non-Pet Owners & $50 \quad$ & 56.8 & 29.4 & \\
\hline \multicolumn{2}{|r}{${ }^{*}$ Significant at 0.05 level } \\
\end{tabular}

The table 1 observed that there is a significant difference on happiness scores between pet owners and nonpet owners. The t-value is 4.42 which is significant at $0.01 \mathrm{p}$ level. The mean of pet owners is higher than non-pet owners as pet owners scored 17.8 on mean score as compared to non- pet owners who scored 12.4 which means that pet owners are happier than non-pet owners. From table 2, it can be observed that there is significant difference on psychological well-being scores between pet owners and non-pet owners. The tvalue is 2.34 which is significant at $0.05 \mathrm{p}$ level. The mean of pet owners is higher than non- pet owners as 
pet owners scored 70.8 on mean score as compared to non- pet owners who scored 56.8 which means that pet owners have better psychological well-being than non- pet owners.

\section{DISCUSSION}

As the tables revealed that there is a significant difference on happiness scores between pet owners and non- pet owners. Thus first hypothesis has been rejected. Pet owners are happier than non- pet owners and living their life to its fullest. The results were similar to the results of study conducted by Stribling [18] which found correlation between people having regular interactions with pets and their happiness. People who had regular interactions with pets reported more happiness with their lives than people who did not have regular interactions with pets. Table 2 shows that there is significant difference on psychological wellbeing scores between pet owners and non- pet owners. Thus second hypothesis has also been rejected. Pet owners have better psychological well-being than non- pet owners. Studies have shown that pets may influence people's health and wellbeing by reducing blood pressure, improving heart attack victim's likelihood of future survival, and by reducing factors of general health and annual medical needs [19].

\section{CONCLUSION}

The result of study can be concluded as pet owners are happier and have better psychological well-being than non- pet owners. Everything that comes for free is priceless. The emotional value of a pet, the unconditional love they provide us is priceless and no amount of money can replace that. The power of pet magic is really quite tremendous.

\section{REFERENCES}

1. Friedmann E, Son H, Tsai C. The animal-human bond: Health and wellness. Handbook on animal-assisted therapy: Theoretical foundations and guidelines for practice 2000:41-58.

2. Johnson RA, Beck AM, McCune S. The health benefits of dog walking for pets and people: evidence and case studies. Purdue University Press; 2011.

3. Johnson TD. Pets can be a prescription for happier, healthier life. Nation's Health 2011;40:10-32.

4. Linley PA, Joseph S. Positive psychology in practice. New Jersey, John Wiley \& Sons, Inc., Hoboken ; 2004.

5. Tkach C, Lyubomirsky S. How do people pursue happiness?: Relating personality, happiness-increasing strategies, and well-being. J Happiness Stud 2006;7(2):183-225.

6. Diener E, Biswas-Diener R. Happiness: Unlocking the mysteries of psychological wealth. John Wiley \& Sons; 2011.

7. Diener E, Sandvik E, Pavot W. Happiness is the frequency, not the intensity, of positive versus negative affect. Assess Well-being 2009:213-31.

8. Frey BS, Stutzer A. The economics of happiness. World Economics 2002;3(1):1-7.

9. Ryff CD. Happiness is everything, or is it? Explorations on the meaning of psychological well-being. J Personal Soc Psychol 1989;57(6):1069-80.

10. Burris JL, Brechting EH, Salsman J, Carlson CR. Factors associated with the psychological well-being and distress of university students. J Am College Health 2009;57(5):536-44.

11. Deci EL, Ryan RM. Hedonia, eudaimonia, and well-being: An introduction. J Happiness Stud 2008;9(1):111.

12. Wells DL. Domestic dogs and human health: An overview. Br J Health Psychology 2007;12(1):145-56.

13. Friedman HS, DiMatteo MR, Taranta A. A study of the relationship between individual differences in nonverbal expressiveness and factors of personality and social interaction. J Res Personality 1980;14(3):35164.

14. McConnell P. For the love of a dog: understanding emotion in you and your best friend. Ballantine Books; 2009.

15. McConnell AR, Brown CM, Shoda TM, Stayton LE, Martin CE. Friends with benefits: on the positive consequences of pet ownership. J Personal Soc Psychol 2011;101(6):1239-45.

16. Bao KJ, Schreer G. Pets and happiness: Examining the association between pet ownership and wellbeing. Anthrozoös 2016;29(2):283-96.

17. Lyubomirsky S. The Longevity Project. Nature 2011;475(7354):32-3. 
18. Stribling A. The Effect of Regular Interaction with Pets and General Happiness. Community of Undergraduate Journals Online; 2003.

19. Odendaal JS. Animal-assisted therapy—magic or medicine?. J Psychosom Res 2000;49(4):275-80.

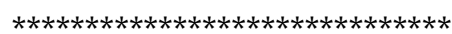

Acknowledgements - Nil

Conflict of Interest - Nil

Funding - Nil 